\title{
Academic Performance Outcomes Before and After Implementation of Blended Teaching-Learning Intervention among Nursing Students in Selected Kenyan Universities
}

\author{
David Kaniaru $^{1 *}$, Anne Karani ${ }^{2}$, Waithira Mirie ${ }^{2}$, Elijah Nyangena ${ }^{3}$ \\ ${ }^{\mathrm{T}}$ School of Nursing Midwifery and Paramedics, Masinde Muliro University of Science and Technology, Kakamega \\ Webuye, Kenya \\ ${ }^{2}$ Nursing and Nursing Education, School of the Nursing Science University of Nairobi, Parklands/Highridge, Prof \\ Mourice Alala Road, Kenya \\ ${ }^{3}$ University of Kabianga, Kabianga Rd Kenya, Kenya
}

\section{*Corresponding Author}

David Kaniaru

\author{
Article History \\ Received: 08.10.2020 \\ Accepted: 25.10 .2020 \\ Published: 17.11.2020
}

\begin{abstract}
Introduction: Many studies to assess the efficacy of Internet-based learning in clinical nurses have been undertaken. The study aimed to compare the resultant learning outcomes following applying blended mode in teachinglearning alongside conventional instructional approaches. The research hypothesized a non-significant difference in academic performance outcomes before and after implementing blended teaching-learning intervention among nursing students in Kenya's selected universities. Methodology: This study applied mixed design methods to obtain detailed information from the study participants of interest to the researcher. Four out of nineteen (4/19) universities in Kenya that offered Bachelor of Science in Nursing were sampled using convenience nonprobability sampling. The sample population included an experimental group and a control group. Only general nursing lecturers and nursing students participated. Data was collected by the use of observation, self-reported questionnaires. Descriptive and inferential data were processed and analyzed in order to generate simplified information. Results: A total population of $(n=486)$ comprised of $175(36.0 \%)$ male and $311(64 \%)$ female participants who consented for the study. The students had a mean age of 22 years. $302(62.1 \%)$ students were motivated to adopt and use the blended mode of learning during the intervention phase while participants strongly agreed during the preintervention phase, 405/486 (83.33\%) agreed, 27/486 $(5.56 \%)$ were neutral, while 39/486 (8.03\%) disagreed. There were 353 observations in the Intervention group and 133 observations in the Control group. The result of the two-tailed Mann-Whitney U test was significant based on an alpha value of $0.05, \mathrm{U}=19280.5, \mathrm{z}=-3.04, \mathrm{p}=.002$. The mean rank for the Intervention group was 65.03and the mean rank for the group Control group was 61.62. This suggests that the distribution of academic performance for the group Intervention group was significantly different from the distribution of academic performance for the Control group category. Recommendations: Although this is observed, there is a need to emphasize sensitization to reduce student's anxiety further and increase to a higher level the engagement and utilization. Further researchers should consider cooperating other relevant variables that were not featured in the current study to reduce the current Knowledge gap in the adoption and implementation of blended learning-teaching in Universities. Conclusion: There is a significant correlation between the utilization of blended teaching and learning mode and nursing students' academic performance among universities offering Bachelor of Science in Nursing in Kenya.
\end{abstract}

Keywords: Utilization, blended Teaching and learning mode, academic performance, Nursing, Kenyan.

\section{INTRODUCTION}

The blended learning approach refers to the systematic integration of online (eLearning) and face-to-face engagement to support and enhance meaningful interaction between the teacher and students, as suggested by Garrison and Kanuka [1]. It is an education program (formal or informal) that combines online digital media with traditional

Copyright (C) 2020 The Author(s): This is an open-access article distributed under the terms of the Creative Commons Attribution 4.0 International License (CC BY-NC 4.0) which permits unrestricted use, distribution, and reproduction in any medium for non-commercial use provided the original author and source are credited. 
classroom instructional methods. More so, it creates a learning experience whereby the learner interacts with other students, with the instructor, and with e-contents.

Blended learning methodology applies to the integrated combination of online (e-learning) and face-to-face communication to promote positive contact between teachers and students, as proposed by Garrison and Kanuka [2]. A blended learning platform is a (formal or informal) style of instruction that combines both modern electronic platforms with conventional classroom instructional methods. The method provides a learning experience that allows the learner to interact with others, course instructors, and the generated learning materials through the thoughtful integration of online commonly known as E-Learning settings at their own pace and time [3].

Many studies to assess the efficacy of Internet-based learning in clinical nurses have been undertaken. The [4] study was used for Education in fire safety, ventilator training, and infection control skills. These studies found that online learning was an efficient way for information to be enhanced and improved job performance [5]. Nevertheless, given these empirical results, as most experiments have been done in fairly limited scales, it is difficult to say that IBL varies greatly from or is better than conventional methods of Education. A meta-analysis was conducted to deal with this problem: for the integrating outcomes, the statistical analysis was applied to the compilation of outcomes from individual studies. These research studies have shown that IBL is an efficient way of teaching outcomes, such as information, ability, learning, and self-effectiveness.

Students enrolling in nursing school pursue various learning methods. They have also faced numerous learning difficulties and have several on-going lifestyle commitments. Besides, as noted by Bloomfield et al., [19], several teaching strategies have been proposed as appropriate when discussing students' varying learning styles and needs. Blended teaching and learning is the therefore essential style that allows for the convergence of face-to-face communication with online interactions. The blended model can also be argued to provide a versatile forum that helps tackle differences seen in learning styles among students [6].

In recent years, the progress made by internet diffusion in educational technology has provided significant acknowledged incentives for enhancing the standard of the varied teaching experience. As Ainsley [7] points out, the Internet has enhanced global communication in real-time, henceforth encouraged better coordination between nursing teachers and nursing students. Currently, the availability of electronic communications equipment and, in particular, Internet connectivity in the world and Kenya has increased [8].

The study aimed to compare the resultant learning outcomes following applying blended mode in teachinglearning alongside conventional instructional approaches. The research hypothesized a non-significant difference in academic performance outcomes before and after implementing blended teaching- learning intervention among nursing students in the selected universities in Kenya

\section{MeTHODOLOGY}

This study to find Utilization of Blended Approach Mode in Teaching and Learning for Undergraduate Nurses in Kenya used mixed methods design with specific application of concurrent triangulation strategies. One public and one private University were deemed to be the experimental group and control group, respectively. Masinde Muliro University of Science and Technology, Maseno University, which are public universities, while Great Lake of Kisumu University and University of Eastern Africa Baraton are private universities. The four universities are located in the western part of Kenya.

Study participants were students from the school of nursing. Purposive sampling was used in identifying fourthyear nursing students. Students were selected randomly by the aid of a random table enabling minimization of biasness in selecting study participants, as noted by Rose [9]. A sample of 486 participants was obtained by $N$ use of Yamane formula [18], $\mathrm{n}=1+N(\mathrm{e})^{2}$ from a target population of 865 . Simple random and purposive sampling methods were used to achieve the desired study sample of 486. All fourth-year registered nursing students were eligible for the study and their respective general nursing lecturers at the study time. All nursing students in their first, second, third year, absent from school, and not registered at the time of the study were not eligible. Plus, all other students who were undertaking any other program in the University during data collection were also deemed to be excluded from the study. A research permit was obtained from NACOSTI Kenya, ERC of the universities' selected university study sites involved in the study. An information sheet, the consent form was also provided and filled by the study participants before the data collection commencement. Besides, anonymity and confidentiality were assured. A self-administered questionnaire was completed by participating students, which consisted of section A, closed-ended questions to capture demographic information. In contrast, Section B adopted a modified five Likert scale items to capture the outcome of academic performance and blended teaching and learning among nursing students in university students. The responses were on a five-point rating of Strong Agree (S.A.)-5, Agree (A)-4, Neutral (N)-3, Disagree (D)-2, and Strongly Disagree (SD)-1. 
The questionnaire was filled before the course was taught and after the teaching of the course, which served as the intervention phase. A control group was also identified, and both the pre-test and the post-test responses were recorded. Experts reviewed the nursing department questionnaire at the University of Nairobi College of Health Science and its contents validated after the pilot study. Statistical Packages for Social Sciences (SPSS) computer packages version 23 was used to code, organize, and analyse it. Descriptive statistics of mean, percentages, standard deviation, frequency distribution was used to summarize data. Chi-square was used to determine the association of the participants' blended learning engagement to their respective universities.

\section{RESULTS}

Four hundred and eighty-six (486) subjects participated in the study. 175 (36.0\%) were male while $311(64.0 \%)$ were female. The respondents were of varied ages between 20 years $(0.4 \%)$ to $37(0.2 \%)$ years of age. The majority were $23(50.6 \%)$ years, followed by $24(14.4 \%)$ years, $25(12.6 \%)$, and $22(4.7 \%)$ years old, respectively. However, the male gender had a mean of 24.8 while the Female gender had a mean of 24.0. Table-1 shows the demographic characteristics of the study subjects.

Among other demographics, the respondents were required to answer which category of University they came from. The target subjects were sampled from public and private universities $64.4 \%$ of the respondents came from public University while $35,6 \%$ came from private universities, as illustrated in Table-2.

Table-1: Respondents mean age

\begin{tabular}{|l|l|l|l|}
\hline Gender & Mean & N & Std. Deviation \\
\hline Male & 24.8229 & $175(36 \%)$ & 3.24968 \\
\hline Female & 24.0289 & $311(64 \%)$ & 2.38323 \\
\hline Total & 24.3148 & $486(100 \%)$ & 2.75038 \\
\hline
\end{tabular}

Table-2: University category of respondents

\begin{tabular}{|l|l|l|}
\hline & Frequency & Percent \\
\hline Public & 313 & $64.4 \%$ \\
\hline Private & 173 & $35.6 \%$ \\
\hline Total & 486 & $100.0 \%$ \\
\hline
\end{tabular}

To determine the influence of the blended method on the degree of involvement, a 2-tailed independent $\mathrm{z}$-test analysis was performed to assess whether the mean post-intervention involvement score between the intervention and control groups was significantly different. The two-tailed, separate z-test tests resulted in a substantial rejection of the null hypothesis, based on an alpha value of $0.05, \mathrm{z}=-2.90, \mathrm{p}-004$. The mean of post-intervention interaction between the Intervention group and the Control group was significantly different from this result. The mean of the Post-intervention engagement score in the intervention group was significantly lower than the mean of the Post-intervention engagement score in the Control group. The null hypothesis was rejected ( $p<0.04)$, leading to the conclusion that there are significant differences in post-intervention engagement scores between the intervention and control groups. The results are presented in Table-3.

Frequencies and percentages were calculated for the ten items used to assess key success factors that lead to acceptance in the use of the blended approach among students. For the Intervention group, most study participants agreed that they knew how e-learning via Moodle classroom works $(n=178,50 \%)$ while for the Control group, most strongly agreed $(n=64,48 \%)$. For the Intervention group, most study participants strongly agreed that they were competent at preparing and accessing e-learning materials $(n=127,36 \%)$ while for the Control group, most study participants agreed $(n=48,36 \%)$. Frequencies and percentages are presented in Table-3.

Table-3: First table of Post-intervention results for Key success factors

\begin{tabular}{|c|c|c|}
\hline Variable & Intervention group & Control group \\
\hline \multicolumn{3}{|c|}{ I know how e-learning via Moodle classroom works } \\
\hline Agree & $178(50 \%)$ & $0(0 \%)$ \\
\hline disagree & $10(3 \%)$ & $42(32 \%)$ \\
\hline Strongly Agree & $159(45 \%)$ & $64(48 \%)$ \\
\hline Strongly Disagree & $6(2 \%)$ & $27(20 \%)$ \\
\hline \multicolumn{3}{|c|}{ I am competent at preparing and accessing e-learning materials } \\
\hline Agree & $75(21 \%)$ & $48(36 \%)$ \\
\hline disagree & $38(11 \%)$ & $21(16 \%)$ \\
\hline Not sure & $103(29 \%)$ & $43(32 \%)$ \\
\hline
\end{tabular}




\begin{tabular}{|l|l|l|}
\hline Strongly Agree & $127(36 \%)$ & $21(16 \%)$ \\
\hline Strongly Disagree & $10(3 \%)$ & $0(0 \%)$ \\
\hline I prefer E-Learning lessons than face to face \\
\hline Agree & $25(7 \%)$ & $5(4 \%)$ \\
\hline disagree & $216(61 \%)$ & $74(56 \%)$ \\
\hline Not sure & $47(13 \%)$ & $11(8 \%)$ \\
\hline Strongly Agree & $16(5 \%)$ & $0(0 \%)$ \\
\hline Strongly Disagree & $49(14 \%)$ & $43(32 \%)$ \\
\hline
\end{tabular}

For the Intervention group, most study participants disagreed that, they were interested in improving their performance through e-learning $(n=332,94 \%)$ while for the control group, the majority were not sure $(n=81,61 \%)$. For the Intervention group, most study participants strongly agreed that they could discipline themselves to participate in e-learning exercise $(n=340,96 \%)$. For Control group, majority strongly agreed $(n=110,83 \%)$. Frequencies and percentages are presented in Table-4.

Table-4: Second table of post-intervention results for Key success factors

\begin{tabular}{|l|l|l|}
\hline Variable & Intervention group & Control group \\
\hline I often use computer/smartphone at home to undertake my study work & \multicolumn{1}{l|}{} \\
\hline Disagree & $97(27 \%)$ & $86(65 \%)$ \\
\hline Not sure & $51(14 \%)$ & $0(0 \%)$ \\
\hline Strongly agree & $198(56 \%)$ & $45(34 \%)$ \\
\hline Strongly disagree & $7(2 \%)$ & $2(2 \%)$ \\
\hline I am interested in improving my performance through e-learning & $332(94 \%)$ & $31(23 \%)$ \\
\hline Disagree & $21(6 \%)$ & $81(61 \%)$ \\
\hline Not sure & $0(0 \%)$ & $8(6 \%)$ \\
\hline Strongly agree & $0(0 \%)$ & $13(10 \%)$ \\
\hline Strongly disagree & $5(1 \%)$ & $19(14 \%)$ \\
\hline I can discipline myself to participate in e-learning exercise & $8(2 \%)$ & $4(3 \%)$ \\
\hline Agree & $340(96 \%)$ & $110(83 \%)$ \\
\hline Not sure & \multicolumn{2}{|l}{} \\
\hline Strongly agree &
\end{tabular}

For the Intervention group, most study participants disagree that the school had enough computers for students' use $(n=97(27 \%)$ while in the control group, the majority strongly agreed $(n=86,65 \%)$. For Intervention $(n=318$, $90 \%)$ and control groups $(n=92,69 \%)$, most study participants strongly agreed that Computers in Department were in good functional status. Frequencies and percentages are presented in Table-5.

Table-5: Third table of Post-intervention results for crucial success factors

\begin{tabular}{|l|l|l|}
\hline \multicolumn{3}{|l|}{ Overly, I prefer the blended teaching and learning mode } \\
\hline Variable & Intervention group & Control group \\
\hline Agree & $324(92 \%)$ & $108(81 \%)$ \\
\hline Not sure & $29(8 \%)$ & $25(19 \%)$ \\
\hline My school has enough computers for students use \\
\hline Agree & $5(1 \%)$ & $3(2 \%)$ \\
\hline Disagree & $270(76 \%)$ & $44(33 \%)$ \\
\hline Strongly agree & $78(22 \%)$ & $86(65 \%)$ \\
\hline Computers in Department is in good functional status \\
\hline Disagree & $5(1 \%)$ & $2(2 \%)$ \\
\hline Not sure & $30(8 \%)$ & $39(29 \%)$ \\
\hline Strongly agree & $318(90 \%)$ & $92(69 \%)$ \\
\hline I have my own computer/laptop, notepad, smartphone for use \\
\hline Variable & Intervention group & Control group \\
\hline Disagree & $102(29 \%)$ & $33(25 \%)$ \\
\hline Not sure & $11(3 \%)$ & $45(34 \%)$ \\
\hline Strongly agree & $238(67 \%)$ & $54(41 \%)$ \\
\hline Strongly disagree & $2(1 \%)$ & $1(1 \%)$ \\
\hline
\end{tabular}


To assess the differences in academic performance between Intervention and Control groups, a two-tailed Mann-Whitney two-sample rank-sum test was conducted. This was to examine whether there were significant differences in academic performance between Intervention and Control groups. The two-tailed Mann-Whitney two-sample rank-sum test is an alternative to the independent samples $t$-test but does not share the same assumptions [10]. There were 353 observations in the Intervention group and 133 observations in the Control group. The result of the two-tailed MannWhitney $U$ test was significant based on an alpha value of $0.05, U=19280.5, z=-3.04, p=.002$. The mean rank for the Intervention group was 65.03and the mean rank for the group Control group was 61.62. This suggests that the distribution of academic performance for the group Intervention group was significantly different from the distribution of academic performance for the Control group category. The intervention group $(M d n=65.03)$ was significantly higher than the median for Control group $(M d n=61.62)$. Table 4.14 presents the result of the two-tailed Mann-Whitney $U$ test. Figure 4.5 presents a boxplot of the ranks of the Post-intervention engagement score by group.

Table-6: Two-Tailed Mann-Whitney Test for academic performance score by group

\begin{tabular}{|l|l|l|l|l|l|}
\hline & \multicolumn{2}{|l|}{ Mean Rank } & & \\
\hline Variable & Intervention group & Control group & U & z & p \\
\hline Post-intervention academic score & 65.03 & 61.62 & 19280.50 & 3.04 & 002 \\
\hline
\end{tabular}

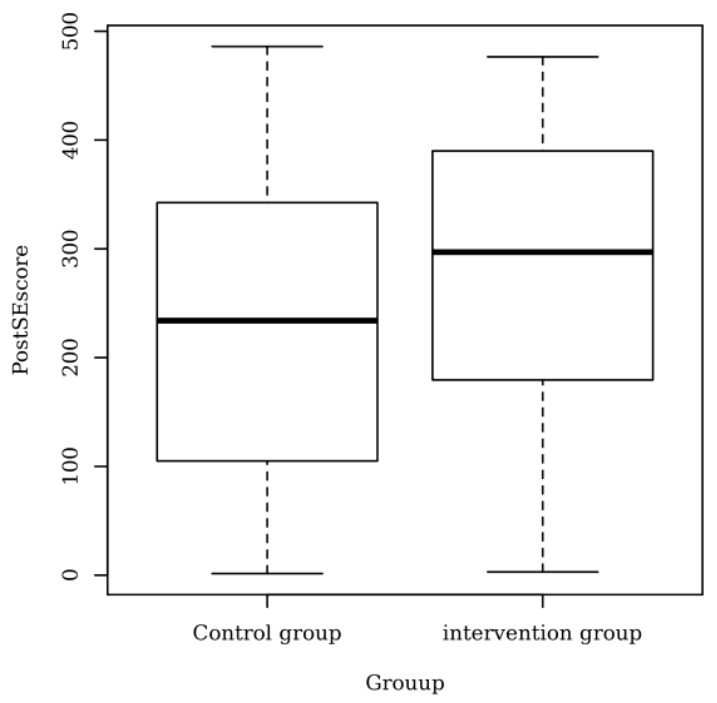

Fig-1: Ranks of Post-intervention engagement score by group

\section{DISCUSSION}

To achieve the third objective, the study sought to determine the effects of implementing blended teachinglearning approaches on engagement level and students' academic performance. The findings of the current study showed that the mean of post-intervention engagement scores was significantly different between Intervention and Control groups.

This was characterized by the post-intervention group posting a higher mean than the preintervention group. This is concurring with several studies that show there is a low but noticeable change in the offering of healthcare knowledge and Education, which compelled the participants to change their critical thinking ability and methods to adapt the use of varied methods of learning healthcare education [11].

The new occurrence brings in a new dispensation in healthcare education and especially Nursing. Learners and teachers are shifting from the use of conventional methods of teaching and learning to non-traditional methods. These phenomena have seen an improved delivery of content from the teachers to the nursing students. Furthermore, modern methods have played a role in defining role-plays during learning and teaching. The improved performance is also attributable to the classroom response system and one-on-one interviews that aids in keeping the learners highly engaged in various manners [12].

Further studies done by Levitt \& Adelman [13] showed that with student engagement during learning, there was a heightened increase in excitement and increased interest. These led to improved course evaluation, making them more positive towards the content and method of learning. The participating students also developed a sustained high level of 
interest in nursing theories and practicum knowledge that superseded the end of the current course. These studies explain the increased mean of the post-intervention group.

More studies continue to show and link the use of these methods to enhanced learners' alertness, critical, discerning, performance, self-assurance, and gratification [14]. These approaches have determined conditions and characters; this has helped create and manage solutions for the management and solving of teaching and learning problems. These methods have enabled the handling of risky situations with safer states and conditions. These methods of learning have also helped to improve patient care. By applying these methods, students have the leeway of making and correcting a mistake in an experiment where the patient's life is not at stake. Though applications and use of these methods, the classroom has been transformed into an active one [15].

Similarly, the mean of the Post-intervention perception score was significantly different between the Intervention group and Control group. This can be attributed to the use of several teaching methods in the post interventional group that led to enhanced experiential expertise. The use of various teaching and learning aids facilitates learners' team effort and cooperation with other small groups.

These interactions between students and teams can enhance students' ability to be highly innovative in seeking other methods that can be used to solve issues in healthcare. Consequently, the interactions have been predicted to increase the student's motivation to work and communicate with classmates and participate in self-education and problem-solving activities. These are the effects of implementing the blended learning approach [16].

The findings suggested that the difference in the mean of the Baseline engagement score and the mean of Postintervention engagement score was significantly different from zero. The current study portrays that within the group, there was a significant exchange of information and knowledge. This is supported by other studies done by Warland, Smith \& Smith [17], which state that professional nurses need competencies to effectively collaborate, connect, and operate together with other healthcare specialists. These interactions help to develop a sound environment that allows the exchange of information and learning. The students can interact among themselves and enhance the horizontal capability to exchange information and make decisions while developing trust among students.

\section{RECOMMENDATION}

The study showed that participants in the selected study sites utilized blended teaching and learning approach mode minimally, as evidenced by high levels of disagreement in the multivariable that were tested to include. The posttest results indicated that most of the respondents had acquired the skills, and their engagement levels had improved significantly. Although this is observed, there is a need to emphasize sensitization to reduce student's anxiety further and increase to a higher level the engagement and utilization.

Further researchers should consider co-operating relevant variables that were not featured in the current study to $\mathrm{r}$ current Knowledge gap in the adoption and implementation of blended learning-teaching in Universities.

In collaboration with the University management team, state educational policymakers should consider the study results significant to inform on review of existing operating standards on virtual learning.

\section{LIMITATIONS}

The outcome of this study is limited in its generalizability and needs to be validated in other settings. This study does not consider university rankings and economic statuses to realize the application of blended approach learning in Nursing.

\section{Conclusion}

There is a significant correlation between the utilization of blended teaching and learning mode and the academic performance of nursing students among universities offering Bachelor of Science in Nursing in Kenya but not fully utilized, as shown in the above and similar studies in the world.

\section{DeClarations}

Ethics Approval: Ethical clearance was obtained from Masinde Muliro University of Science and Technology Ethics Committee. Consent. 
Competing interest: The authors declare that they have no competing interests.

Disclaimer: The findings and conclusions presented in this manuscript are those of the authors and do not necessarily reflect the official position of Masinde Muliro University.

\section{REFERENCES}

1. Garrison, D. R., \& Kanuka, H. (2004). Blended learning; uncovering its transformative potential in higher Education. 7: 95-105.

2. Garrison and Kanuka (2011

3. Arbough, J. B. (2008). Managing the Online classroom. A study of Technology and Behavioural Characteristics of web-based MBA courses. Journal of high technology management Research. 3: 2003-223.

4. Ahmad, T., Ibrahim, H., Moh. Yusof, S. A. (2011). Issues and Challenges in Applying Computer Based Distance Learning system as an alternative to traditional training methods. GSTF. Intentional Journal of computing. 1(2):231237.

5. Kusemo, N. S., Kurniawan, F. B., \& Putri N. I. (2012). E-learning obstacle faced by Indonesian students. The eightinternational conference on eLearning for a knowledge-based society.

6. Bonk, C., \& Graham, C. (Eds.). (2006). the Handbook of Blended learning: global perspectives.

7. Ainsley, B., \& Brown, A. (2009). The Impact of Informatics on Nursing Education: A Review of the Literature. The Journal of Continuing Education in Nursing. 40(5), 228-32.

8. Basaki, S. (2016). Information \&Technology and Education; the case study of learning in Indonesia'. KoreanASEAN Academic Conference on information Revolution and cultural integration in East Asia. International journal of Science and technology. 16:127-133.

9. Rose, M. N. (2007): Foundations of Nursing Research; 6th Ed Pearson Education New Jersey.

10. Conover, W. J., \& Iman, R. L. (1981). Rank transformations as a bridge between parametric and nonparametric statistics. The American Statistician, 35(3), 124-129.

11. Kidd, L. I., Knisley, S. J., \& Morgan, K. I., 2012. Effectiveness of a second life (®) simulation as a teaching strategy for undergraduate mental health nursing students. Journal of Psychosocial Nursing and Mental Health Services, 50(7), 28-37.

12. Parasuram, R., Huiting, X., Wang, J., Thirumarban, A., Eng, H. J. K., \& Lien, P. C. (2014). Effectiveness of using non-traditional teaching methods to prepare student health care professionals for the delivery of the Mental State Examination: a systematic review protocol. JBI Database of Systematic Reviews and Implementation Reports, 12(8), 3-19.

13. Levitt, C., \& Adelman, D. S. (2010). Role-playing in nursing theory: Engaging online students. Journal of Nursing Education, 49(4), 229-232.

14. Cato, M. L., Lasater, K., \& Peeples, A. I. (2019). Nursing students' self-assessment of their simulation experiences. Nursing Education Perspectives, 30(2), 105-8.

15. Gore, T., Hunt, C. W., \& Raines, K. H. (2018). Mock hospital unit simulation: A teaching strategy to promote safe patient care. Clinical Simulation in Nursing, 4(3), e57-e64.

16. Chan, Z. C. (2012). Role-playing in the problem-based learning class. Nurse Education in Practice, 12(1), 21-7.

17. Warland, J., Smith, C., \& Smith, M. (2012). Much ado about the flu: Design and implementation of an e-role play for a large class of undergraduate students. Nurse Education in Practice, 12(2), 65-71.

18. Yamane, T. (1967). Statistics: An Introductory Analysis, 2nd Edition, New York: Harper and Row.

19. Bloomfield, J. G., While, A. E., \& Roberts, J. D. (2008). Using Computer Assisted Learning for Clinical Skills Education in Nursing: integrative review. Advance Journal of Nursing. 63(3): 222-35. 